\title{
Seroepidemiology of human enterovirus71 and coxsackievirusA16 among children in Guangdong province, China
}

Wei Li $i^{1,2,3 \dagger}$, Lina $\mathrm{Yi}^{1,4 \dagger}$, Juan Su ${ }^{1,2,3}$, Jing Lu ${ }^{1,4}$, Hanri Zeng ${ }^{1,2,3}$, Dawei Guan ${ }^{1,2,3}$, Cong Ma ${ }^{1,2,3}$, Wanly Zhang ${ }^{1,2,3}$, Hong xiao ${ }^{1,2,3}$, Hui Li ${ }^{1,2,3}$, Yonghui Zhang ${ }^{1,2,3}$, Jinyan Lin ${ }^{1,2,3}$ and Changwen Ke $\mathrm{e}^{1,2,3^{*}}$

\begin{abstract}
Background: Hand, foot and mouth disease (HFMD) is a common pediatric illness. Mainly induced by the Enterovirus 71 and Coxsackievirus A 16 infections, the frequently occurred HFMD outbreaks have become a serious public health problem in Southeast Asia. Currently,only a few studies have investigated the human immunity to HFMD in China. In this study, we conducted a cohort study in Guangdong province, China.

Methods: Stored serum samples from children less than 10 years old were analyzed. The levels of EV71 and CA16 specific antibodies before, during and shortly after the 2008 large outbreak of HFMD were evaluated by the microneutralization test. The geometric mean titer (GMT) was calculated and compared. Statistical significance was taken as $\mathrm{P}<0.05$.

Results: The seroprevalence data showed a continuous circulation of EV71 and CA16 in Guangdong province China in 2007-2009. The low positive rate in 2009 correlated well with the unprecedented outbreak of HFMD in 2010. Age related increase of seroprevalence was identified in 1-3 years old children for EV71 and in 1-5 years old children for CA16 in Guangdong province. High GMT of EV71 and CA16 antibody titers were also found for these age groups.

Conclusions: All of the above findings indicated common infections for these age groups. And they should clearly be at the top of the priority in periodical seroprevalence survey and future vaccination campaign.
\end{abstract}

Keywords: Enterovirus 71, Coxsackievirus A 16, Seroprevalence

\section{Background}

Hand, foot and mouth disease (HFMD) is a common pediatric illness [1]. It is characterized by $3-4$ days of fever and then the development of vesicles on the palmar and plantar skin, buccal mucosa and tongue [2-4]. This illness as itself is mild and self-limited [5]. While in some cases, accompanied with other neurological complications, HFMD may also lead to severe outcomes and

\footnotetext{
* Correspondence: kecw1965@yahoo.com.cn

${ }^{\dagger}$ Equal contributors

${ }^{1}$ Department of Pathogen Detection Research for Emerging Infectious Diseases, Center for Disease Control and Prevention of Guangdong Province, Guangzhou, China

${ }^{2}$ Key Laboratories of Pathogen Detection for Emergency Response, Center for Disease Control and Prevention of Guangdong Province, Guangzhou, Guangdong, China

Full list of author information is available at the end of the article
}

even death [6-8]. Children under 10 years old especially those less than 5 are the most susceptible population for reasons that are not clearly understood [2,9-11].

The first viral agent identified for HFMD is Coxsackievirus A 16 (CA16) [12]. Belonging to the picornaviridae family, this virus, associated with Enterovirus 71 (EV71), is responsible for nearly all of the HFMD epidemics in Southeast Asia [13,14]. In Japan, CA16 was reported to be a prevalent type, while EV71 recurrent every 3 years [10,15]. In Singapore, from 2001 to 2008, the predominant EV strains isolated from HFMD cases were CA16 and EV71 [16,17]. In China, EV71 and CA 16 are also frequently reported to co-circulate and cause HFMD, although the major etiologic agent identified from hospitalized cases was EV71 $[18,19]$.

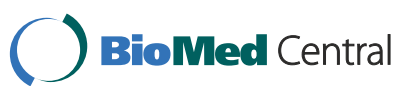

(c) 2013 Li et al.; licensee BioMed Central Ltd. This is an Open Access article distributed under the terms of the Creative Commons Attribution License (http://creativecommons.org/licenses/by/2.0), which permits unrestricted use, distribution, and reproduction in any medium, provided the original work is properly cited. 
Many large HFMD outbreaks with severe and fatal outcomes in Southeast Asia have recently been described $[4,20]$. In Taiwan, the most severe HFMD outbreak occurred in 1998, resulting in 405 severe neurological cases and 78 deaths $[21,22]$. In China, the recent outbreaks of HFMD were initiated from 2007 in Shandong province. Then a national widespread epidemic occurred in 2008, with more than 176,000 reported human cases [23]. Contrary to HFMD outbreaks in other Asian countries, the epidemics in China were more lasting [24]. Unprecedented HFMD outbreaks occurred in the following years. By the end of 2010 , a total of $3,419,149$ cases and 1384 fatal cases were reported $[25,26]$. It is said that the recently occurred HFMD epidemics have become a serious public health problem in Southeast Asia, especially in China.

Currently,only a few studies have been conducted to investigate the human immunity to HFMD in China $[27,28]$. The seroepidemiology of EV71 infection before, during and shortly after the epidemics could pave ways for prophylactic intervention strategies. In addition, several EV71 vaccine candidates are being developed in mainland China from 2008 [29-31]. And some of them are at various stages of clinical development [32,33]. To better establishing the immunization program against EV71 and CA16 infection, seroepidemiological surveillance is urgently needed. In this study, we conducted a cohort study in Guangdong province, China. Children less than 10 years old were enrolled. The levels of EV71 and CA16 specific antibodies in children aged between 1 and 9 years were evaluated and compared for 3 years (2007-2009).

\section{Methods}

\section{Serum samples collection}

The material used in this study is stored serum samples collected from the health children $\leq 9$ years of age who had participated in seasonal immune status surveillance at Guangdong Provincial Centre for Disease Control and Prevention, China, from 2007 to 2009. Survey questionnaire was completed by trained interviewers and included information on the subject's age, gender, vaccination history (over the past year) and presence/absence of illnesses (over the past year). All children had no sign of disease at the time of sample collection. The serum samples were stored at $-80^{\circ} \mathrm{C}$ until testing. For the use of these serum samples, written informed consents from all participants (their parents or legal guardians) involved in survey were obtained. Serum samples from children who reported fever and vesicular exanthema on their hands, feet, mouths, or buttocks (distinct clinical presentation of HFMD) over the past year were excluded in this study and were classified into seven age groups $(1,2,3,4,5,6-7$ and 8-9 years). Each group has 35-40 samples, except age group 1, 2 years in 2007(3 in 1 year group, 24 in 2 year group) and 8-9 years group in 2008 and 2009 (24 and 23 samples respectively). The sex ratios of boys to girls were 1.36:1, 1.43:1, and 1.25:1 respectively. The demographic profile of the subjects is shown in Table 1. The study was approved by the ethics committee of the Guangdong Provincial Center for Disease Control and Prevention, and was in compliance with the Helsinki Declaration.

\section{Neutralizing antibody assay}

The neutralizing antibody (NA) tests were performed as previously described [34]. To define the EV71 neutralizing antibody, EV71/Guangdong/EV039/2009 (C4 genotype) strain was used, which is isolated from a fatal case in 2009. For CA16, CA16 Guangdong/CA010/2009 (A genotype) strain was used. All of the neutralizing antibody assays were run in 96-well microplates. Serum samples were inactivated at $56^{\circ} \mathrm{C}$ for 30 minutes before use, diluted two-fold from $1: 8$ to $1: 1,024$, and then incubated at $37^{\circ} \mathrm{C}$ for 2 hours with equal volumes of 100 half tissue culture infective doses (100 TCID50) of EV71 or CA16. After the incubation period, $1 \times 10^{5}$ cells $/ \mathrm{ml}$ rhabdomyosarcoma cell lines (RD) were added to each well. Finally, these plates were incubated in a $5 \% \mathrm{CO} 2$ incubator at $37^{\circ} \mathrm{C}$ for 7 days. And the CPE was observed with an inverted microscope from the fourth day. All the diluted samples were tested in duplicate. Cell control, serum control and virus control were included in each plate. Viral back titration was conducted in each test. The antibody titer of the sample was defined as the highest dilution that could inhibit cytopathic effect (CPE) development in 50\% of the virus-infected wells. A titer equal to or greater than 8 were considered as seropositive.

Table 1 Demographic profile of the subjects in three years studied

\begin{tabular}{cccc}
\hline \multicolumn{2}{c}{$\begin{array}{c}\mathbf{2 0 0 7} \\
\text { No. samples }\end{array}$} & $\begin{array}{c}\mathbf{2 0 0 8} \\
\text { No. samples }\end{array}$ & $\begin{array}{c}\mathbf{2 0 0 9} \\
\text { No. samples }\end{array}$ \\
\hline Age groups (years) & & & \\
1 & 3 & 35 & 36 \\
2 & 24 & 34 & 35 \\
3 & 36 & 39 & 38 \\
4 & 40 & 38 & 37 \\
5 & 39 & 39 & 39 \\
$6-7$ & 40 & 39 & 37 \\
$8-9$ & 40 & 24 & 23 \\
Gender & & & 136 \\
Male & 128 & 146 & 109 \\
Female & 94 & 102 & 245 \\
Total & 222 & 248 & \\
\hline
\end{tabular}




\section{Statistical analysis}

Statistical analyses were performed with SPSS version 13.0. Differences with an error probability of $\mathrm{P}<0.05$ were regarded as significant. For categorical data, we used Chi-square testing and Fisher Exact testing as appropriate. Neutralizing antibody titers of positive serum samples were log-transformed to calculate the geometric mean titer (GMT) and 95\% confidence intervals (CI). Kruskal-Wallis test was used for comparison of the GMT by year and age group. Antibody titers $>1: 1204$ were assigned a value of 1204 .

\section{Results}

\section{Overall seroprevalence of EV71 and/or CA16}

EV71 and CA16 NA are widely identified in the population in three years tested (Table 2). The seroprevalence of NA to EV71 was found to be $44.6 \%$ (95\% CI 38.0-51.0\%), 46.4\% (95\% CI 40.2-52.6\%) and 31.8\% (95\% CI 26.037.6\%) in 2007, 2008 and 2009 respectively. EV71 NA seroprevalence in 2009 showed an obvious decreased trend when compared to that of 2007 and 2008 ( $\mathrm{p}<0.05)$. Related to EV71, higher seroprevalence was observed for CA16 NA in same years except for 2008 ( $<<0.05)$. In 2007, 70.3\% (95\% CI 64.3-76.3\%) individuals were seropositive for CA16 NA. Seroprevalence in 2008 and 2009 was significantly lower than that of 2007 ( $p<0.05)$, with similar values ranged between $51.6 \%$ (95\% CI 45.4$57.8 \%$ ) and $47.3 \%$ (95\% CI 41.0-53.6\%).

Of all tested individuals, 32.4\% (95\% CI 25.8-38.2\%) and 29.4\% (95\% CI 23.3-34.7\%) revealed neutralizing antibodies against both viruses in 2007 and 2008 (Table 2). Then the seroprevalence decreased greatly $(\mathrm{p}<0.05)$, showing a value of $20.4 \%$ (95\% CI 15.0-25.0\%) in 2009.

Table 2 Overall seroprevalence of EV71 and/or CA16 antibody

\begin{tabular}{lcccc}
\hline & & \multicolumn{3}{c}{ No. (\%) positive } \\
\cline { 4 - 5 } Year & No. tested & Enterovirus 71 & Coxsackie A16 & Co-infection \\
\hline $\mathbf{2 0 0 7}$ & & & & \\
Male & 128 & $52(40.6)$ & $92(71.9)$ & $39(30.4)$ \\
Female & 94 & $47(50.0)$ & $64(68.1)$ & $33(35.1)$ \\
Total & 222 & $99(44.6)$ & $156(70.3)$ & $72(32.4)$ \\
$\mathbf{2 0 0 8}$ & & & & \\
Male & 146 & $64(43.8)$ & $77(52.7)$ & $43(29.5)$ \\
Female & 102 & $51(50.0)$ & $51(50.0)$ & $30(29.4)$ \\
Total & 248 & $115(46.4)$ & $128(51.6)$ & $73(29.4)$ \\
$\mathbf{2 0 0 9}$ & & & & \\
Male & 136 & $47(34.6)$ & $68(50.0)$ & $31(22.8)$ \\
Female & 109 & $31(28.4))$ & $48(44.0)$ & $19(17.4)$ \\
Total & 245 & $78(31.8)$ & $116(47.3)$ & $50(20.4)$ \\
\hline
\end{tabular}

No significant gender specific difference in seroprevalence was observed for both EV71 and CA16 NA (Table 2). 40.6\% (95\% CI: 32.1 - 49. 4\%) of boys tested EV71 NA seropositive, compared to 50.0\% (95\% CI: 40.0 - 60.2\%) among girls in 2007. While for CA16 NA, the seroprevalence was $71.9 \%$ (95\% CI: 64.0-79.6\%) and 68.1\% (95\% CI: $58.7-78.9 \%$ ) respectively. Values in 2008 were $43.8 \%$ (boys, 95\% CI: 36.2-52.4\%) and 50.0\% (girls, 95\% CI: 40.5-60.3\%) for EV71 NA, 52.7\% (boys, 95\% CI: 45.2-61.2\%) and 50.0\% (girls, 95\% CI: 40.5-60.3\%) for CA16 NA. 34. 6\% (95\% CI 26.4-43.5\%) boys and $50.0 \%$ (95\% CI 41.2-59.3\%) boys showed neutralizing antibodies to EV71 and CA16 respectively in 2009. The proportion of EV71/CA16 seropositive girls was $28.4 \% / 44.0 \%$.

\section{Age-dependent seroprevalence of EV71 and/or CA16}

The analysis of the different age groups $(n=35-40)$ revealed a general increasing trend for EV71 NA seroprevalence in all of the three years tested, except for a slight dip at the age of 2 years group in 2008 and 2009 (Figure 1A). The percentage of EV71 NA positive individual increased from $0 \%, 28.6 \%$ and $11.1 \%$ in the first group (age 1 year group; 2007, 2008 and 2009 respectively) to plateau values no less than $40 \%, 48.7 \%$ and $36.8 \%$ among 3 to 9 years old individual. No obvious rise or decline was observed for these age groups.

While for CA16, it showed much higher seroprevalence than EV71 in nearly all of the age group in three years tested except in year 2008. Similar with EV71 NA seroprevalence, an age related increase of CA16 NA seropositive individuals was observed (Figure 1B). In 2007, children 2 years old had a seroprevalence of $45.8 \%$, and thereafter reached to at least $61.1 \%$ in $3-5$ years groups, then this value stated at approximately $85 \%$ for those aged 6 or older. Compared to 2007, the age dependent curves in 2008 and 2009 both showed significant reduction at 2 years group. CA16 NA seroprevalence declined from $28.6 \%$ and $30.5 \%$ at 1 year group to $5.8 \%$ and $8.5 \%$ at 2 year group in 2008 and 2009 respectively. Then these values steady increased to at least $66.7 \%$ for children aged 5 or old in 2008 , and to $59.5 \%$ for children aged 4 or old in 2009.

A moderate percentage was obtained when testing neutralizing antibodies against both EV71 and CA 16 (Figure 1C). Children among 2-3 years old had a value of $20.0 \%$, and $30.0 \%$ at age 4 , and then reached at $40.0 \%$ for the subsequent groups in 2007. In 2008 and 2009, the lowest level of NA seroprevalence for these two viruses was $2.9 \%$ and $0.0 \%$ respectively, both were found at age 2. Thereafter the NA seroprevalence stated at appoximately $30.0 \%$ among 3-9 years children. 


\section{A}

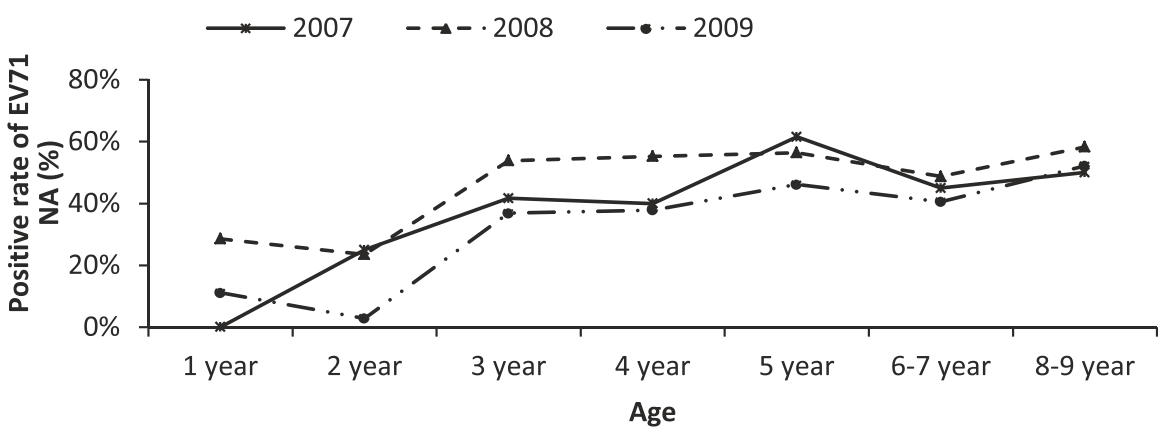

B

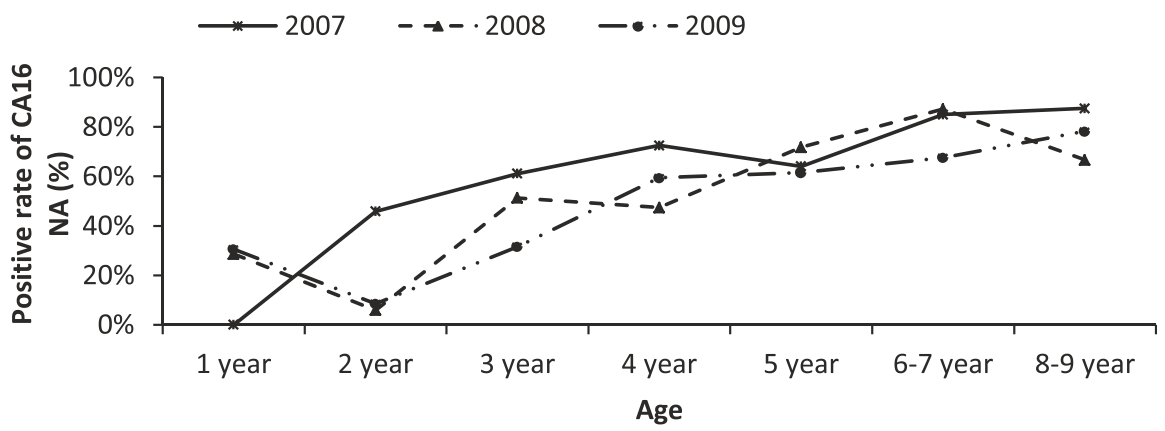

C

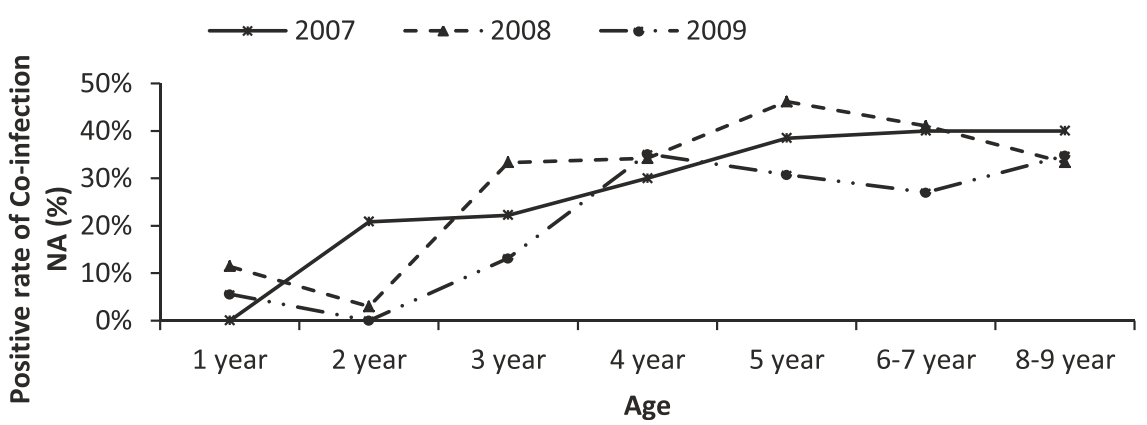

Figure 1 Age-dependent seroprevalence of EV71 and/or CA16 antibody. Age-related seroprevalence of neutralizing antibodies to EV71 (A), CA16 (B), or both of these two viruses (C) in individuals in Guangdong, China.

\section{Geometric mean titer distribution of EV71 and CA16} neutralizing antibodies in seropositive individuals

To analyze the immunity level, the geometric mean titer (GMT) of EV71 and CA16 neutralizing antibodies in seropositive individuals was tested. The overall EV71 NA showed a moderate level, with GMT values of 51.6 (95\% CI:40.6-64.5), 88.1 (95\% CI:71.3-108.9) and 56.6 (95\% CI:41.6-76.8) in 2007, 2008 and 2009 respectively (Figure 2). For CA16, significant higher values were observed than those for EV71 in each year tested $(\mathrm{p}<0.05)$ (Figure 2). The highest CA16 antibody level was identified in 2007, with a value of 175.5 . Then the GMT values gradually declined to 143.4 and 135.8 in 2008 and 2009 respectively (Figure 2 ).

GMT values of EV71 NA were slightly higher in 1-5 years group than in those 5 years older. The highest
GMT of EV71 in 2007 was in children aged 2 years group (GMT 114.0). Then this value reduced across age groups, fell to approximately 40.0 among those 5 years or older (Figure 3A). Compared to 2007, the GMT in 2008 was relatively high in most of the age groups. Children in 1-5 years groups had values no less than 87.7. Then the immunity level decreased to 39.8 and 60.9 in children aged 6-7 and 8-9. In 2009, the highest GMT was identified in 1 year old children (GMT 128.0). Contrary to 2007, the 2 years group had a lowest value of 8 in 2009 . Then this value gently increased with age, rising from 39.0 to 101.6 in 3-5 year groups. Again, for those aged more than 5 years, the GMT in seropositive individuals was relatively low. No one was found to be more than 50.0. For CA16 (Figure 3B), the GMT values were approximately equally distributed in 2007 and 2008 . 


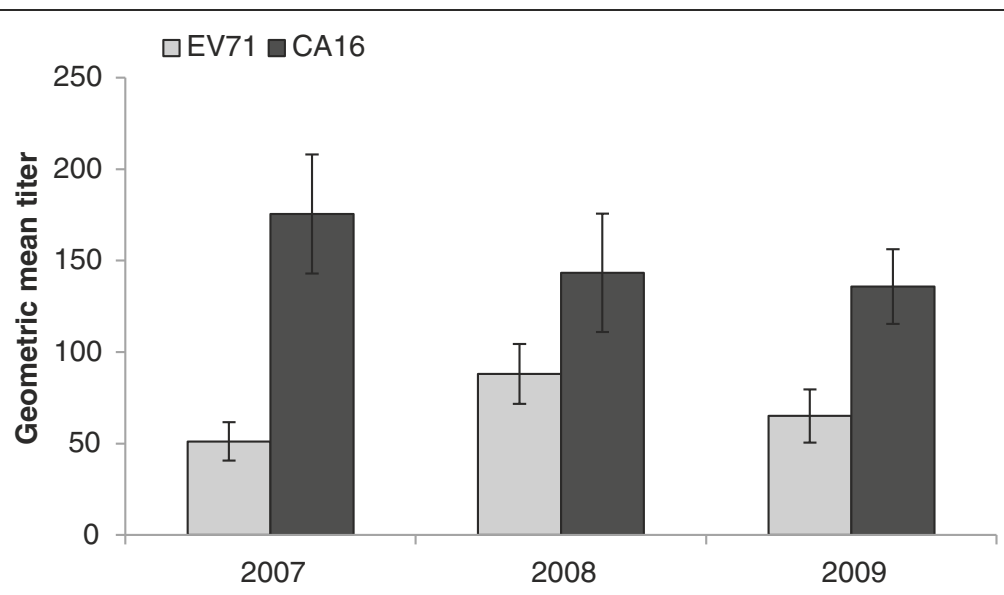

Figure 2 Geometric mean titer (GMT) of EV71 and CA16 antibody in seropositive individuals. The lines indicate $95 \%$ confidence interval.

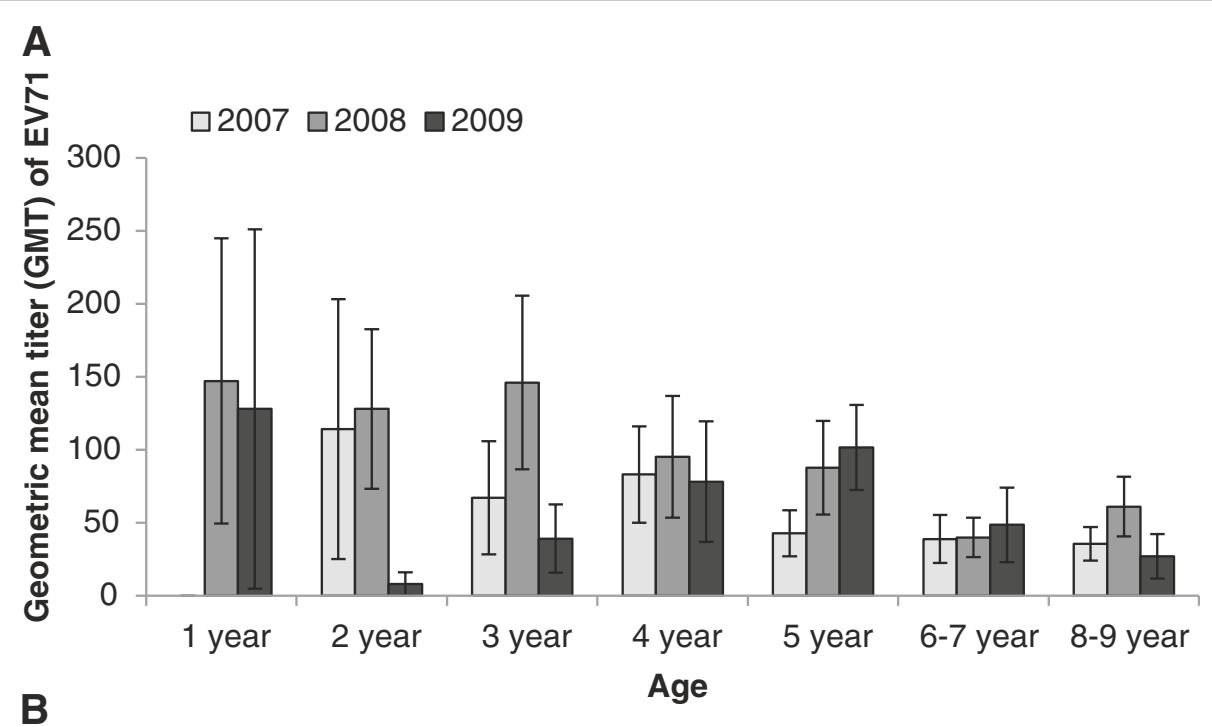

B

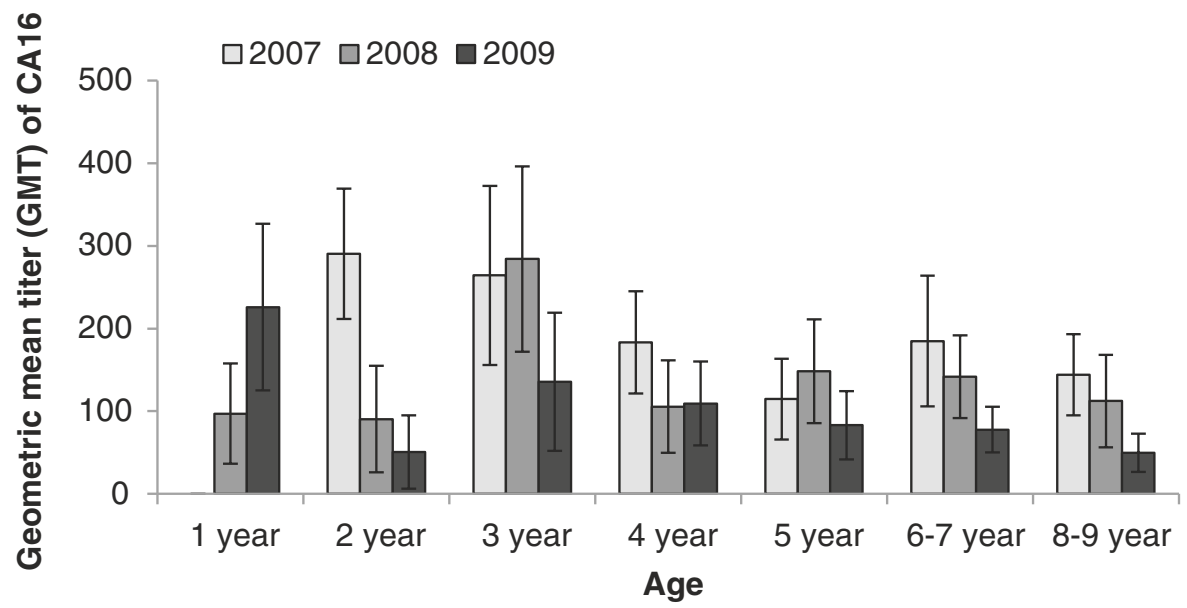

Figure 3 Geometric mean titer (GMT) of EV71 and CA16 antibody by age group. Age-related geometric mean titer (GMT) of EV71 (A) and CA16 (B) antibody in seropositive individuals. The lines indicate $95 \%$ confidence interval. 
Significant higher values were only observed in $2-3$ years groups in 2007 and in 3 year group in 2008. While in 2009, declining trend across age was identified, with a sudden dip at age of 2 years.

\section{Discussion}

In humans, humoral immunity with neutralizing antibodies played central roles in anti viral infection [35-37]. Recent vaccine studies in animal model also demonstrated the protective effects of neutralizing antibody in EV71 challenge [38,39]. In addition, surveillance data in other countries also suggested a causative role for the decreased herd immunity in susceptible population during HFMD outbreaks [40]. To date, few surveillance data were reported on seroepidemiology of EV71 and CA16 in China. In this study, the neutralizing antibodies against EV71 and CA16 among children in Guangdong were investigated. Seroprevalence changes before, during and shortly after the national widespread epidemic in 2008 were described.

In China, HFMD was first reported in Shanghai in 1981, and since then, sporadic cases of HFMD in other provinces including Beijing, Fujian, Shandong, Hubei, Jilin were reported in 1980s. Recently the epidemic situation of HFMD in China tended to be more serious. In 2007, nearly 40,000 HFMD cases were reported in Shandong and over 10,000 cases were recorded in large cities such as Beijing and Shanghai [41]. However, little reports have described the HFMD situations in Guangdong in 2007. Our results suggested moderate EV71 infections occurred among the children in Guangdong before the large HFMD epidemic in 2008. The overall seroprevalence of EV71 NA in 2007 was similar to those in 2005 in Guangdong, as well as those in 2006-2007 in Lu'an $[42,43]$. About half of children less than 10 years old had no neutralizing antibody against EV71. Compared to EV71, significant higher positive rate of neutralizing antibody against CA16 in 2007 was identified. This was contrary to a previous study, which suggested more common EV71 infections in South China in 2005 [42]. The high CA16 seroprevalence in 2007 indicated that frequent asymptomatic and/or unrecognized CA16 infections have occurred before and in this year. In 2008, among 936 laboratory-confirmed cases, EV71 was found in $59 \%$ and CA16 in 26\% [19]. Considering the protective effects of neutralizing antibody in viral infection, the epidemiology surveillance data in 2008, to some degree, had verified our results. The seroprevalence of EV71 and CA16 in this year could serve as HFMD trends predictors for next year.

In March 2008, a serious HFMD epidemic with 20 deaths broke out in Fuyang City, Anhui Province, and subsequently spread quickly in almost all provinces of China [44]. After that, the Ministry of Health of China classified HFMD as one of the category "C" notifiable diseases. According to the Guangdong HFMD webbased surveillance system, a total of 47,660 HFMD cases were reported in 2008. And this number almost doubled in 2009 (92,998 reported cases), was five-fold in 2010 (230,978 reported cases) [41]. To correlate the level of immune protection to the incidence rate of HFMD cases, seroprevalence of EV71 and CA16 NA in and after the 2008 were also investigated. We didn't find significant higher positive rate of EV71 and CA16 in and after 2008. Previous study suggested that HFMD presents a seasonal pattern every 2-3 years [45]. Together with the increased incident rates of HFMD cases in 2009-2010, our results suggested that the peak of recent HFMD epidemic cycle in Guangdong was not in year 2008 but in the years 2009 and 2010. Consistent with these, $\mathrm{Yu}$, et al. identified that children in Lu'an had significant higher seropositive rate in 2010 when compared to that before 2008 [43]. The ensuing HFMD epidemics from 2008 to 2010 largely increased the exposed chance of viral infection and thus the seropositive rate of viral NA in children.

EV71 and CA16 were highly diverse in the nucleotide sequences of structure proteins which serve as major antigen in host immune response. Li et al. used VP1s and VP4s as antigens to detect of serum antibodies against EV71 and CA16 [46]. Their results suggested immunological reaction to VP1 and VP4 of both EV71 and CA16 was different. The study from the clinical patient also indicated that individuals with or without prior EV71neutralizing antibody showed a similar incidence of non-71 Enterovirus infection [47]. EV71 and CA16 were the most common causes of HFMD diseases in recent epidemics in China [44]. To evaluate the immune protection level against HFMD, we also calculated the proportion of individuals that were positive for both the EV71 and CA16. In total, about $30.0 \%$ of all tested individuals had antibodies both to EV71 and to CA16 before and during the 2008 epidemic, while this rate greatly reduced to $20.0 \%$ in year 2009 . The large number of susceptible individuals may be partly responsible for the large outbreak of HFMD in Guangdong in 2010. Similar with reports in other countries, the dates in our study also proved that individual susceptible probability depends on the protective level of neutralizing antibodies. Epidemic occurred when herd immunity decreased.

As a common febrile illness of early childhood, HFMD occurred mainly among children $\leq 5$ years old. In Guangdong, a total of 47,660 and 92,998 cases have been reported to the provincial surveillance system in 2008 and 2009 respectively. The number of children $\leq 5$ years old accounted for the largest proportion (from $87.5 \%$ to 93.3\%) [48]. These were highly consistent with the age related seroprevalence trends in our study. In our 
results, both EV71 and CA16 NA rise with age among children less than 5 years and reach a plateau thereafter $[34,49]$. We also observed significant reduction at 2 years group, the most susceptible population that had the highest incidence rates of HFMD in 2008 and 2009 epidemic year in Guangdong. In 2007, the lowest seroprevalence was identified in 1 year old children. While for children in 2 year old group, slightly high positive rate was shown. Epidemic waves before and in this year could not be traced. Whether this different seroprevalence trend in 2007 provided an accurate picture, or it just was the result of very small number of cases in 1 year group remains to be determined by future investigations.

The GMT for EV71 and CA16 was also analyzed. All the seropositive individuals in three years tested showed relative high CA16 NA levels (Figure 2). Unlike a previous report conducted in Jiangsu province China, which showed low antibody titers against CA16 in children aged 2-15 years, the high GMT observed in this study suggested common CA16 infections in Guangdong province [27]. In addition, our data also suggested that most of the EV71 infections are acquired when they were less than 5 years old, while for CA16, mainly occurred among 1-3 years groups (Figure 3), because the highest antibody titers were observed in these age groups and neutralizing antibody titers were high at early stage of infection. GMT for both the EV71 and CA16 were all declined among children 5 years or older, which account for about $10 \%$ of the total reported HFMD cases [48]. The relative low level of EV71 and CA16 NA in these less susceptible populations indicated a critical role for the long-lasting immunity rather than immunity level in protecting against viral infection.

\section{Conclusions}

Altogether, the seroprevalence data in our study showed a continuous circulation of EV71 and CA16 in Guangdong province China in 2007-2009. The relative high seropositive rates in healthy children indicated many clinically silent EV71/CA16 infections in these years. These seropositive children that had asymptomatic or unrecognized EV71/CA16 infection may serve as a reservoir for continued viral spread in the population, and should be taken into account when the government develops and implements public health interventions. Consistent with previous studies, age related increase of seroprevalence was also identified in 1-5 years children in Guangdong, which indicated common infections for these age groups. And they should clearly be at the top of the priority in periodical seroprevalence survey and future vaccination campaign.

\section{Competing interests}

The authors declare that they have no competing interests.

\section{Authors' contributions}

YL and KC drafted the manuscript. LW, SJ, LJ, ZH, GD, MC, ZW and XH carried out the laboratory tests, $L H, Z Y$ and $L J$ performed the statistical analyses. All authors read and approved the final manuscript.

\section{Acknowledgement}

This work was supported by National Major Projects of Major Infectious Disease Control and Prevention, the Ministry of Science and Technology of the People's Republic of China (2012ZX10004213-004) and Guangdong Provincial Scientific Plan (2012B031500007).

\section{Author details}

${ }^{1}$ Department of Pathogen Detection Research for Emerging Infectious Diseases, Center for Disease Control and Prevention of Guangdong Province, Guangzhou, China. ${ }^{2}$ Key Laboratories of Pathogen Detection for Emergency Response, Center for Disease Control and Prevention of Guangdong Province, Guangzhou, Guangdong, China. ${ }^{3}$ Key Laboratories of Depository and Application for Pathogenic Microbiology, Center for Disease Control and Prevention of Guangdong Province, Guangzhou, Guangdong, China.

${ }^{4}$ Guangdong Provincial Institution of Public Health, Guangzhou, Guangdong, China.

Received: 17 March 2013 Accepted: 10 July 2013

Published: 15 July 2013

\section{References}

1. Yi L, Lu J, Kung HF, He ML: The virology and developments toward control of human enterovirus 71. Crit Rev Microbiol 2011, 37(4):313-327.

2. Solomon T, Lewthwaite P, Perera D, Cardosa MJ, McMinn P, Ooi MH: Virology, epidemiology, pathogenesis, and control of enterovirus 71. Lancet Infect Dis 2010, 10(11):778-790.

3. Hsiung GD, Wang JR: Enterovirus infections with special reference to enterovirus 71. J Microbiol Immunol Infect 2000, 33(1):1-8.

4. Chen SC, Chang HL, Yan TR, Cheng YT, Chen KT: An eight-year study of epidemiologic features of enterovirus 71 infection in Taiwan. Am J Trop Med Hyg 2007, 77(1):188-191.

5. McMinn PC: An overview of the evolution of enterovirus 71 and its clinical and public health significance. FEMS Microbiol Rev 2002, 26(1):91-107.

6. Koroleva GA, Lukashev AN, Khudiakova LV, Mustafina AN, Lashkevich VA: Encephalomyelitis caused by enterovirus type 71 in children. Vopr Virusol 2011, 55(6):4-10

7. Denizot M, Neal JW, Gasque P: Encephalitis due to emerging viruses: CNS innate immunity and potential therapeutic targets. J Infect 2012, 65(1):1-16

8. McMinn P, Stratov I, Nagarajan L, Davis S: Neurological manifestations of enterovirus 71 infection in children during an outbreak of hand, foot, and mouth disease in Western Australia. Clin Infect Dis 2001, 32(2):236-242.

9. Shih SR, Stollar V, Li ML: Host factors in enterovirus 71 replication. J Virol 2011, 85(19):9658-9666.

10. Suzuki Y, Taya K, Nakashima K, Ohyama T, Kobayashi JM, Ohkusa Y, Okabe N: Risk factors for severe hand foot and mouth disease. Pediatr Int 2009, 52(2):203-207.

11. Lee MS, Chiang PS, Luo ST, Huang ML, Liou GY, Tsao KC, Lin TY: Incidence rates of enterovirus 71 infections in young children during a nationwide epidemic in Taiwan, 2008-09. PLoS Negl Trop Dis 2012, 6(2):e1476.

12. Tu PV, Thao NT, Perera D, Huu TK, Tien NT, Thuong TC, How OM, Cardosa MJ, McMinn PC: Epidemiologic and virologic investigation of hand, foot, and mouth disease, southern Vietnam, 2005. Emerg Infect Dis 2007, 13(11):1733-1741.

13. Wei SH, Huang YP, Liu MC, Tsou TP, Lin HC, Lin TL, Tsai CY, Chao YN, Chang LY, Hsu CM: An outbreak of coxsackievirus A6 hand, foot, and mouth disease associated with onychomadesis in Taiwan, 2010. BMC Infect Dis 2011, 11:346.

14. Mirand A, Henquell C, Archimbaud C, Ughetto S, Antona D, Bailly JL, Peigue-Lafeuille $\mathrm{H}$ : Outbreak of hand, foot and mouth disease/ herpangina associated with coxsackievirus A6 and A10 infections in 2010, France: a large citywide, prospective observational study. Clin Microbiol Infect 2012, 18(5):E110-118.

15. Iwai M, Masaki A, Hasegawa S, Obara M, Horimoto E, Nakamura K, Tanaka Y, Endo K, Tanaka K, Ueda J, et al: Genetic changes of coxsackievirus A16 and enterovirus 71 isolated from hand, foot, and mouth disease patients 
in Toyama, Japan between 1981 and 2007. Jpn J Infect Dis 2009, 62(4):254-259.

16. Wu Y, Yeo A, Phoon MC, Tan EL, Poh CL, Quak SH, Chow VT: The largest outbreak of hand; foot and mouth disease in Singapore in 2008: the role of enterovirus 71 and coxsackievirus A strains. Int J Infect Dis 2010, 14(12):e1076-1081

17. Ang LW, Koh BK, Chan KP, Chua LT, James L, Goh KT: Epidemiology and control of hand, foot and mouth disease in Singapore, 2001-2007. Ann Acad Med Singapore 2009, 38(2):106-112.

18. Guan D, van der Sanden S, Zeng H, Li W, Zheng H, Ma C, Su J, Liu Z, Guo X, Zhang $X$, et al: Population dynamics and genetic diversity of $C 4$ strains of human enterovirus 71 in Mainland China, 1998-2010. PLoS One 2012, 7(9):e44386

19. Sun LM, Zheng HY, Zheng HZ, Guo X, He JF, Guan DW, Kang M, Liu Z, Ke CW, Li JS, et al: An enterovirus 71 epidemic in Guangdong Province of China, 2008: epidemiological, clinical, and virogenic manifestations. Jpn J Infect Dis 2011, 64(1):13-18.

20. Chan LG, Parashar UD, Lye MS, Ong FG, Zaki SR, Alexander JP, Ho KK, Han $L L$, Pallansch MA, Suleiman AB, et al: Deaths of children during an outbreak of hand, foot, and mouth disease in sarawak, malaysia: clinical and pathological characteristics of the disease. For Outbreak Study Group Clin Infect Dis 2000, 31(3):678-683.

21. Lee MS, Lin TY, Chiang PS, Li WC, Luo ST, Tsao KC, Liou GY, Huang ML, Hsia SH, Huang YC, et al: An investigation of epidemic enterovirus 71 infection in Taiwan, 2008: clinical, virologic, and serologic features. Pediatr Infect Dis J 2010, 29(11):1030-1034.

22. Centers for Disease Control and Prevention, Taiwan: Deaths among children during an outbreak of hand, foot, and mouth disease--Taiwan, Republic of China, April-July 1998. MMWR Morb Mortal Wkly Rep 1998, 47(30):629-632.

23. Zhang J, Sun J, Chang Z, Zhang W, Wang Z, Feng Z: Characterization of hand, foot, and mouth disease in China between 2008 and 2009. Biomed Environ Sci 2011, 24(3):214-221.

24. Tan X, Huang X, Zhu S, Chen H, Yu Q, Wang H, Huo X, Zhou J, Wu Y, Yan D, et al: The persistent circulation of enterovirus 71 in People's Republic of China: causing emerging nationwide epidemics since 2008. PLoS One 2011, 6(9):e25662.

25. Liu MY, Liu W, Luo J, Liu Y, Zhu Y, Berman H, Wu J: Characterization of an outbreak of hand, foot, and mouth disease in Nanchang, China in 2010. PLoS One 2011, 6(9):e25287.

26. Yan XF, Gao S, Xia JF, Ye R, Yu H, Long JE: Epidemic characteristics of hand, foot, and mouth disease in Shanghai from 2009 to 2010: Enterovirus 71 subgenotype $C 4$ as the primary causative agent and a high incidence of mixed infections with coxsackievirus A16. Scand J Infect Dis 2011, 44(4):297-305.

27. Ji H, Li L, Liu Y, Ge H, Wang X, Hu J, Wu B, Fu J, Zhang Z, Chen X, et al: Seroepidemiology of human enterovirus 71 and coxsackievirusA16 in Jiangsu province. China Virol J 2012, 9(1):248.

28. Zeng M, El Khatib NF, Tu S, Ren P, Xu S, Zhu Q, Mo X, Pu D, Wang X Altmeyer R: Seroepidemiology of Enterovirus 71 infection prior to the 2011 season in children in Shanghai. J Clin Virol 2012, 53(4):285-289.

29. Mao Q, Dong C, Li X, Gao Q, Guo Z, Yao X, Wang Y, Gao F, Li F, Xu M, et al: Comparative analysis of the immunogenicity and protective effects of inactivated EV71 vaccines in mice. PLoS One 2012, 7(9):e46043.

30. Lee MS, Tseng FC, Wang JR, Chi CY, Chong P, Su IJ: Challenges to licensure of enterovirus 71 vaccines. PLoS Negl Trop Dis 2012, 6(8):e1737.

31. Liang Z, Mao Q, Gao Q, Li X, Dong C, Yu X, Yao X, Li F, Yin W, Li Q, et al: Establishing China's national standards of antigen content and neutralizing antibody responses for evaluation of enterovirus 71 (EV71) vaccines. Vaccine 2011, 29(52):9668-9674.

32. Meng FY, Li JX, Li XL, Chu K, Zhang YT, Ji H, Li L, Liang ZL, Zhu FC: Tolerability and immunogenicity of an inactivated enterovirus 71 vaccine in Chinese healthy adults and children: an open label, phase 1 clinical trial. Hum Vaccin Immunother 2012, 8(5):668-674.

33. Li YP, Liang ZL, Gao Q, Huang LR, Mao QY, Wen SQ, Liu Y, Yin WD, Li RC, Wang JZ: Safety and immunogenicity of a novel human Enterovirus 71 (EV71) vaccine: a randomized, placebo-controlled, double-blind, Phase I clinical trial. Vaccine 2012, 30(22):3295-3303.

34. Rabenau HF, Richter M, Doerr HW: Hand, foot and mouth disease: seroprevalence of Coxsackie A16 and Enterovirus 71 in Germany. Med Microbiol Immunol 2009, 199(1):45-51.
35. Tarr AW, Urbanowicz RA, Ball JK: The role of humoral innate immunity in hepatitis C virus infection. Viruses 2012, 4(1):1-27.

36. Minor PD: The polio-eradication programme and issues of the end game. J Gen Virol 2011, 93(Pt 3):457-474.

37. Abraham RS: Relevance of antibody testing in patients with recurrent infections. J Allergy Clin Immunol 2012, 130(2):558-559. e556.

38. Liang Y, Zhou X, Yang E, Pu J, Che Y, Wang J, Ma N, Liu L, Ding D, Tang D, et al: Analysis of the Th1/Th2 reaction in the immune response induced by EV71 inactivated vaccine in neonatal rhesus monkeys. J Clin Immunol 2012, 32(5):1048-1058.

39. Mao Q, Li N, Yu X, Yao X, Li F, Lu F, Zhuang H, Liang Z, Wang J: Antigenicity, animal protective effect and genetic characteristics of candidate vaccine strains of enterovirus 71. Arch Virol 2011, 157(1):37-41.

40. Buxbaum S, Berger A, Preiser W, Rabenau HF, Doerr HW: Enterovirus infections in Germany: comparative evaluation of different laboratory diagnostic methods. Infection 2001, 29(3):138-142.

41. Liu Y, Wang X, Sun D, Ding S, Zhang B, Du Z, Xue F: Detecting SpatialTemporal Clusters of HFMD from 2007 to 2011 in Shandong Province. China PLoS One 2013, 8(5):e63447.

42. Zhu Z, Zhu S, Guo X, Wang J, Wang D, Yan D, Tan X, Tang L, Zhu H, Yang Z, et al: Retrospective seroepidemiology indicated that human enterovirus 71 and coxsackievirus A16 circulated wildly in central and southern China before large-scale outbreaks from 2008. Virol J 2010, 7:300.

43. Yu H, Wang M, Chang H, Lu J, Lu B, Li J, Chen W, Tang R, Gan L, Zhao J, et al: Prevalence of antibodies against enterovirus 71 in children from Lu'an City in Central China. Jpn J Infect Dis 2011, 64(6):528-532.

44. Zhu Q, Hao Y, Ma J, Yu S, Wang Y: Surveillance of hand, foot, and mouth disease in mainland China (2008-2009). Biomed Environ Sci 2011, 24(4):349-356.

45. Yu SC, Hao YT, Zhang J, Xiao GX, Liu Z, Zhu Q, Ma JQ, Wang Y: Using interrupted time series design to analyze changes in hand, foot, and mouth disease incidence during the declining incidence periods of 2008-2010 in China. Biomed Environ Sci 2012, 25(6):645-652.

46. Li Y, Zhu R, Qian Y, Deng J, Sun Y, Liu L, Wang F, Zhao L: Comparing Enterovirus 71 with Coxsackievirus A16 by analyzing nucleotide sequences and antigenicity of recombinant proteins of VP1s and VP4s. BMC Microbiol 2011, 11:246.

47. Huang WC, Huang LM, Kao CL, Lu CY, Shao PL, Cheng AL, Fan TY, Chi H, Chang LY: Seroprevalence of enterovirus 71 and no evidence of crossprotection of enterovirus 71 antibody against the other enteroviruses in kindergarten children in Taipei city. J Microbiol Immunol Infect 2011, 45(2):96-101.

48. Deng T, Huang Y, Yu S, Gu J, Huang C, Xiao G, Hao Y: Spatial-temporal clusters and risk factors of hand, foot, and mouth disease at the district level in Guangdong Province. China PLoS One 2013, 8(2):e56943.

49. Ang LW, Phoon MC, Wu Y, Cutter J, James L, Chow VT: The changing seroepidemiology of enterovirus 71 infection among children and adolescents in Singapore. BMC Infect Dis 2011, 11:270.

doi:10.1186/1471-2334-13-322

Cite this article as: Li et al:: Seroepidemiology of human enterovirus71 and coxsackievirusA 16 among children in Guangdong province, China. BMC Infectious Diseases 2013 13:322.

\section{Submit your next manuscript to BioMed Central and take full advantage of:}

- Convenient online submission

- Thorough peer review

- No space constraints or color figure charges

- Immediate publication on acceptance

- Inclusion in PubMed, CAS, Scopus and Google Scholar

- Research which is freely available for redistribution 